\title{
A Dynamic Model for Expansion Planning of Multi Echelon Multi Commodity Supply Chain
}

\author{
Mahdi Bashiri , Hossein Badri
}

\begin{abstract}
This paper proposes a dynamic mixed integer linear program (MILP) for design and planning a multi echelon multi product supply chain. The main focus of this paper is the expansion of supply chain from a strategic view point. Here we consider some potential points for establishment of production units and warehouses during planning horizon in which two types of warehouses (private, public) have been considered. Development of the designed supply chain will be planned according to cumulative net income from the first period. This model aim to select suppliers, determine quantity of each raw material to be supplied by each supplier, quantity of each product to be produced in each production unit, quantity of each product to be sent to each warehouse, and quantity of each product to be sent to each market and some other strategic and tactical decisions in order to maximize net profit of the supply chain.
\end{abstract}

Index Terms-Strategic supply chain planning; dynamic modeling; linear programming.

\section{INTRODUCTION}

In today's competitive trade world, manufacturers face the continuing challenge to constantly evaluate and configure their production and distribution systems and strategies to provide the desired customer service at the lowest possible cost. Long-range survival for manufacturing firms will be very difficult to attain without highly optimized strategic and tactical logistics systems. Savings in the 5-10\% range, which can be achieved by using strategic and tactical logistics models, can dramatically affect the profitability of the corporation [6].

The logistics systems design problem is defined as follows: given a set of potential suppliers, potential manufacturing facilities, and distribution centers with multiple possible configurations, and customers with deterministic demands, determine the configuration of the production-distribution system and the transfer prices between various subsidiaries of the corporation such that seasonal customer demands and service requirements are met and the after tax profit of the corporation is maximized.

The after tax profit is the difference between the sales revenue minus the total system cost and taxes. The total cost is defined as the sum of supply, production, transportation,

Manuscript received October 9, 2009

M. Bashiri is with the Department of Industrial engineering, Shahed University, Tehran, Iran (e-mail: Bashiri@shahed.ac.ir).

$\mathrm{H}$. Badri is student of master of Industrial engineering, Shahed University, Tehran, Iran (e-mail: h_badri123@yahoo.com). inventory, and facility costs [6].

A major thrust of recent research in this area is the development of optimization models that integrate different functions (e.g. purchasing, production and distribution) in the supply chain. The basic idea behind this approach is to simultaneously optimize decision variables of different functions that have traditionally been optimized sequentially [9].

One of the most important strategic problems is supply chain optimization. Strategic designing of a supply chain makes the following decisions necessary for logistics engineers and managers:

- Number of production units needed to satisfy customer demands

- Number of warehouses needed for inventories

- Determination capacity of the production units and warehouses

- Supplier selection

- Design of distribution channels

- Quantity of raw materials to be purchased from each supplier

- Quantity of finished products to be produced in each production unit

- Quantity of finished products to be stored in each warehouses

There are several models have been developed to help managers in designing and planning of their supply chain. Arntzen et al. [2] developed a global integrated model based on mixed integer linear programming for production and distribution planning with multiple products and a network of sellers. Amiri [1] proposed a mixed integer linear model to select the optimum numbers, locations and capacities of plants and warehouses to open so that all customer demand is satisfied at minimum total costs of the distribution network in a three echelon, single period and single product. In this paper an efficient heuristic solution procedure for this supply chain system problem has been provided.

Wouda et al. [11] developed a mixed integer linear programming model for optimization of the supply network of Nutricia Hungaryusing. Their model focus was on consolidation and product specialisation of plants, the objective was to find the optimal number of plants, their locations and the allocation of the product portfolio to these plants, when minimizing the sum of production and transportation costs. Cordeau et al. [3] propose a static model for a multi-commodity, multiple facility and single-country network. This model has been developed to determine the 
number of locations, the capacity and technology of manufacturing in plants and warehouses, selection of suppliers, selection of distribution channels, transportation modes and material flows. To solve this problem, the authors present two methods: a simplex-based branch-and bound approach and a Benders decomposition approach.

Noorul Haq and Kannan [8] developed an integrated supplier selection and multi-echelon distribution inventory model in a built-to-order supply chain involving single selected supplier, multiple plants, multiple distributors, multiple wholesalers and multiple retailers. Hamer-Lavoie and Cordeau [4] developed a dynamic model with stochastic demands, which takes inventories into account, including the safety stock. They suppose that the location has already been chosen for plants and the model focuses on warehouse location. The authors propose a linear approximation for the last constraints concerning safety stock and a branch-and-bound method strengthened by valid inequalities. Dias et al. [5] work on the re-engineering of a two-echelon network (facilities and customers). The authors suppose that facilities can be opened, closed and reopened more than once during the planning horizon. They study these conditions within three scenarios: with maximum capacity restrictions; with both maximum and minimum capacity restrictions; and with a maximum capacity that decreases. All of these problems are solved by primal-dual heuristics. In this paper, three linear formulations correspond to the three previous scenarios and their linear dual formulations are presented.

Melo et al. [7] aim at relocating the network with expansion/ reduction capacity scenarios. Capacity can be exchanged between an existing facility and a new one, or between two existing facilities under some conditions. Each change of capacity is penalised by a cost. In this model, closed facilities cannot be reopened, and new facilities will remain in activity until the end of the planning horizon. Thanh et al. [10] proposes a dynamic mixed integer linear programming model for a four echelon supply chain including suppliers, manufacturing firms, distribution centers and customers. Bill of materials and multiple products have been taken into consideration. This paper aims to help strategic and tactical decisions: opening, closing or enlargement of facilities, supplier selection, flows along the supply chain. They make a distinction between a private warehouse (owned by the company) and a public warehouse (hired by the company). The status of a public warehouse can change more than once during the planning horizon.

\section{PRoposed Model}

In this paper we consider a multi-period, multi-commodity multi-facility supply chain problem in which there is a set of potential locations, where a new plant or a new warehouse can be opened. This problem includes four main layers composed of suppliers, production units, distribution centers and customers. The bill of materials is also taken into consideration.

The proposed model aims to make some strategic decisions related to design and planning a supply chain expansion during a planning horizon: selection of suppliers; location and time of facilities opening; planning capacity for existing facilities; production and distribution planning. Inventories also have been taken into consideration.

We assume that there are some potential points that can be selected for establishment of plants and warehouses. Two types of warehouses have been considered in this model: private and public. We assume that the opened plants and private warehouses cannot be closed during the planning horizon. Also hiring a public warehouse for less than $m$ periods is not permitted.

The various assumptions involved in this paper are described below:

- Public warehouses have no fixed costs but their variable costs are higher than those of private warehouses.

- Products only can be transferred from each supplier to all plants, from each plant to all distributors and from each distributor to all customer zones.

- Transfers between plants and between warehouses are not permitted.

- Each supplier has a restriction on the available raw materials.

- Each facility has an initial capacity as well as a limited maximal installable capacity.

- For each facility a set of capacity options are available. The capacity of a facility can be increased by adding capacity options.

- Minimal and maximal rates of utilization for each facility have been considered to avoid facilities running at $1 \%$ or at $100 \%$ of their capacity.

- Transportation cost per product from each supplier to all plants plant, from each plant to all distributors, from each distributor to all customer zones remains fixed for all the periods given.

- Processing cost per product at any plant and inventory cost per product per period at all warehouses remains fixed for all the periods given

- Customer demand is deterministic but it's not necessary to satisfy all customer demands.

The objective function is to maximize total net profit over the time periods computed by subtracting total cost from total revenue. The total revenue is simply the total selling income. The total cost includes the fixed costs of opening facilities, adding facility options, operating facility and variable costs of raw material, production, inventory and transportation.

\section{A. Mixed integer linear programming model}

\section{Notation:}

The following indices, parameters and decision variables are defined.

\begin{tabular}{|c|c|}
\hline$I N V^{t}$ & investment in period $\mathrm{t}$ \\
\hline$T(t \in T)$ & planning horizon \\
\hline $\mathcal{F}^{t}$ & $\begin{array}{l}\text { cumulative net profit from the beginning of } \\
\text { the planning to }(t-1)^{\text {th }} \text { period }\end{array}$ \\
\hline $\ln c^{t}$ & net profit in period $t$ \\
\hline$D L^{t}$ & $\begin{array}{l}\text { cumulative net profit after tax and } \\
\text { stakeholders share from the beginning of } \\
\text { the planning to }(t-1)^{\text {th }} \text { period }\end{array}$ \\
\hline
\end{tabular}


$\mathcal{R}$

$\varepsilon$

$R_{g p}^{t}$

$i c_{i}$

$m c_{i}$

$i u_{i}$

$m u_{\mathrm{i}}$

$K T_{0}$

$\bar{S}_{\bar{f}}$

$D_{c p}^{t}$

$B_{p^{y} p}$

$L T_{\mathrm{p}_{2} \mathbb{1}}$

$L S_{\mathrm{p}, j}$

$\mathrm{A}_{\mathrm{i}, \mathrm{j}}$

$\mathcal{P R}_{\text {p, }}$

PS

$\mathrm{Co}_{\mathrm{i}}$

$\operatorname{Cop}_{\mathrm{i}_{\Perp} \mathrm{O}}$

$C U_{\mathrm{i}}$

$C A_{\mathrm{i}_{1} \mathrm{O}}$

$C P_{p, i}$

$C S_{p, j}$

$C T_{p, i=j}$

$C D_{\text {pigi }}$

$C F_{p \text { pile }}$

$x_{\mathrm{i}}^{\mathrm{t}}$

$y_{i=0}^{t}$

$z_{g p}^{t}$

$f_{p, i}^{t} j_{j}$

$9 p_{i}^{t}$

$h_{p, j}^{t}$ tax rate

stakeholders share (in percent)

set of suppliers

set of plants

set of warehouses

set of private (permanent) warehouses

set of public (hired) warehouses

set of capacity options

set of customers

set of products

set of raw materials

set of finished products

a large number

total profit

total return after sales

total expenses

available capacity of supplier $s$ for $p$ at $t$

initial production capacity at $i$

maximal installable production capacity at $i$

minimal percentage of utilization of facility

$i$

maximal percentage of utilization of

facility $i$

capacity of option $o$

initial storage capacity at $j$

demand of customer $c$ for product $p$ at $t$

quantity of $p^{\prime}$ necessary to manufacture a unit of $p$ (bill of materials)

workload for the treatment of a unit $p$ at facility $i$

workload for the storage of a unit $p$ at warehouse $j$

number of deliveries from plant $i$ to warehouse $j$ in one period

selling price of item of unit $p$ to customer $c$ price of item of unit $p$ from supplier $s$

fixed cost for opening a facility at a potential location $i$

fixed cost for operating capacity option $o$ at facility $i$

fixed cost for operating a facility $i$

fixed cost for adding capacity option $o$ to facility $i$

treatment cost of a unit $p$ at facility $i$ storage cost of a unit of $p$ at warehouse $j$ transportation cost of a unit of $p$ from $i$ to $j$ transportation cost of a unit of $p$ from $s$ to $i$ transportation cost of a unit of $p$ from $j$ to $c$ 1 if the entity $i$ is active at $t ; 0$ otherwise 1 if the capacity option $o$ is added to $i$ at t; 0 otherwise

1 if the supplier $s$ is selected for the raw material $p$ at $t ; 0$ otherwise

quantity of product $p$ transferred from location $i$ to $j$ at $t$

quantity of product $p$ produced in plant $i$ at $t$

quantity of product $p$ held in warehouse $j$ at the beginning of $t$

\section{Objective Function:}

The objective function is to maximize total net profit over the time periods computed by subtracting total cost from total revenue.

$$
\text { Maximize } \mathcal{F}=(\mathcal{R}-\varepsilon)
$$

The total revenue is simply the total selling income:

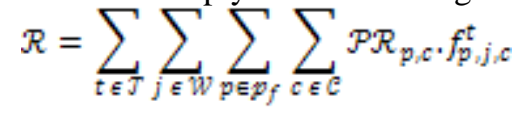

The total cost includes the fixed costs of opening facilities, adding facility options, operating facility and variable costs of raw material, production, inventory and transportation.

$$
\begin{aligned}
& \varepsilon=\sum_{t \in J} \sum_{i \in \mathcal{M} U W y} \operatorname{Co}_{\mathrm{i}} \cdot\left(x_{\mathrm{i}}^{t}-x_{\mathrm{i}}^{t-1}\right)
\end{aligned}
$$

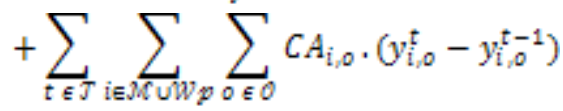

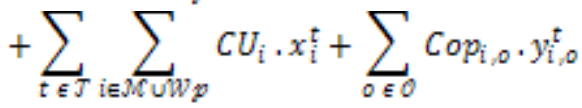

$$
\begin{aligned}
& +\sum_{t \in J} \sum_{p \in y_{f}} \sum_{i \in \mathcal{X}} C P_{p, i} \cdot g_{p, i}^{t}
\end{aligned}
$$

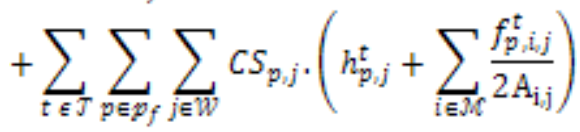

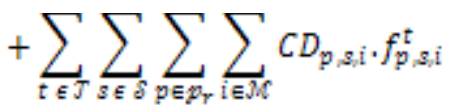

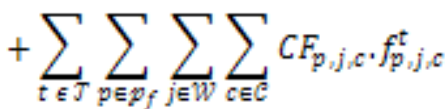

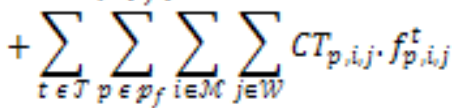

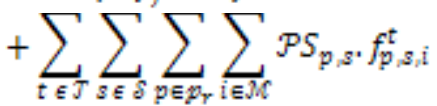

Equation (3) calculates fixed costs of opening facility including plants and warehouses. (4) calculates costs related to adding capacity options to plants and warehouses. (5) defines the operating facility fixed cost, (6) is related to production variable costs and (7) calculates storage variable costs. Equations (8)-(10) are related to transportation costs respectively from supplier $s$ to plant $i$, from warehouse $j$ to customer $c$ and from plant $i$ to warehouse $j$. Equation (11) calculates the raw material supply costs.

\section{Constraints}

$$
\sum_{j \in \mathbb{W}} f_{p_{j}, c}^{t} \leq D_{c p}^{t} \quad \forall c \in C_{v} \forall p \in \mathcal{P}_{f}
$$

Constraint (12) states that all products transferred to costumers should not be more than their demands in any period and it's not necessary to satisfy all customer demands.

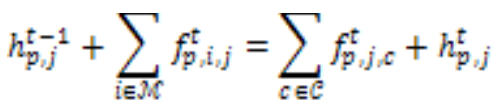

$$
\begin{aligned}
& \forall j \in W_{v} \forall p \in p_{f}
\end{aligned}
$$


Constraint (13) is related to flow conservation at warehouses.

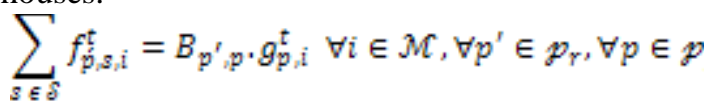

Constraint (14) ensures that plants receive enough raw materials in order to produce the required quantity of finished products.

$$
g_{p, i}^{t}=\sum_{j \in \mathbb{W}} f_{p_{i, j}}^{t} \quad \forall i \in M M_{s} \forall p \in p_{f}
$$

Constraint (15) states that the quantity of manufactured products at a plant should be equal to its delivered quantity to warehouses.

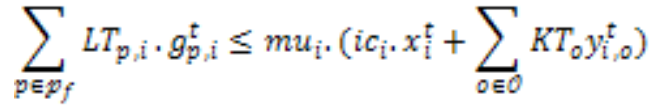

$$
\begin{aligned}
& \forall i \in M
\end{aligned}
$$

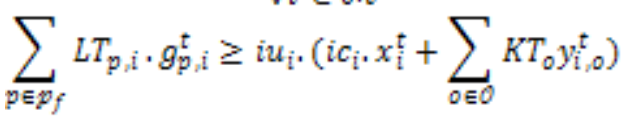

$$
\begin{aligned}
& \forall i \in M
\end{aligned}
$$

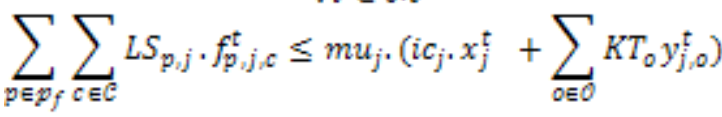

$$
\begin{aligned}
& \forall j \in W p
\end{aligned}
$$

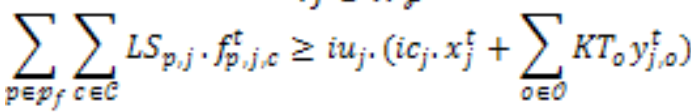

$$
\begin{aligned}
& \forall j \in W p
\end{aligned}
$$

Constraints (16)-(19) are related to capacity of plants and warehouses. These constraints prevent a facility to function under its minimum rate of utilization and to exceed the maximum rate of utilization of its installed capacity. The installed capacity is the sum of the initial capacity and the capacity of the added options.

$$
\begin{aligned}
& \sum_{p \in y_{f}} L S_{p, j^{*}}\left(h_{p, j}^{t}+\sum_{i \in N^{\prime}} \frac{1}{2 A_{i, j}} \cdot f_{p, i, j}^{t}\right) \leq \bar{S}_{j} x_{j}^{t}+\sum_{0 \in 0} K T_{0} \cdot y_{j, 0}^{t} \\
& \forall j \in W p
\end{aligned}
$$

$i c_{i} \times x_{i}^{t}+\sum_{0 \in 0} K T_{0} \cdot y_{i, 0}^{t} \leq m c_{i} \quad \forall i \in M$

$$
i c_{j}, x_{j}^{t}+\Sigma_{0 \in 0} K T_{0} \times y_{j, 0}^{t} \leq m c_{j} \quad \forall j \in W \mathcal{P}
$$

Warehouses must not store more than their storage capacity (20). Also the installed capacity at any plants and any warehouse must not exceed its maximal installable capacity (21)-(22).

$$
\begin{aligned}
& \sum_{i \in \mathcal{M}} f_{p, g i}^{t} \leq z_{g, p^{*}}^{t} R_{g, p}^{t} \quad \forall s \in \mathcal{S}_{v} \forall p \in p_{r} \\
& \sum_{i \in \mathcal{M}} f_{p, q i}^{t} \geq \alpha_{,} z_{g_{p}}^{t} \quad \forall s \in \mathcal{S}_{s} \forall p \in p_{y}
\end{aligned}
$$

Suppliers deliver a raw material if and only if they are selected for this raw material (23) and their delivery cannot exceed their capacity. Constraint (24) is to avoid purchasing each raw material less than predetermined minimal amount of the delivered quantity of each supplier.

$$
\begin{aligned}
& \operatorname{In} c^{t}=\sum_{j \in \mathbb{W}} \sum_{p \in y_{f}} \sum_{\in \in \mathbb{E}} \mathcal{P R}_{p, c} f_{p j, c}^{t} \\
& -\sum_{i \in \text { RUT }} \operatorname{Co}_{\mathrm{i}} \cdot\left(x_{\mathrm{i}}^{t}-x_{\mathrm{i}}^{t-1}\right)
\end{aligned}
$$

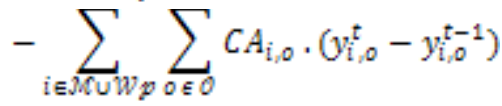

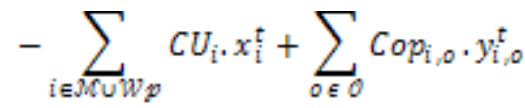

$$
\begin{aligned}
& -\sum_{p \in y_{f}} \sum_{i \in V^{\prime}} C P_{p_{i} i} \cdot g_{p i i}^{t}
\end{aligned}
$$

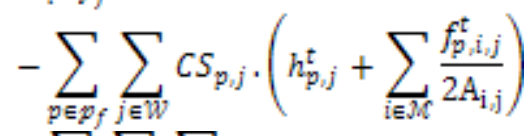

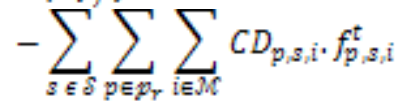

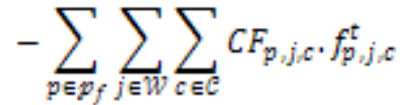

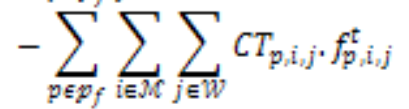

$$
\begin{aligned}
& -\sum_{g \in \delta} \sum_{p \in y_{t}} \sum_{i \in \mathbb{R}} \mathcal{P} S_{p, g} f_{p, g i}^{t} \\
& F^{t}=\sum_{t=1}^{t-1} \ln c^{t} \\
& D L^{t}=(1-T R) \cdot(1-S H) \cdot \mathcal{F}^{t}
\end{aligned}
$$

$\sum_{i \in J \operatorname{MUN}_{p}} \mathrm{Co}_{\mathrm{i}} \cdot\left(x_{\mathrm{i}}^{\mathrm{t}}-x_{\mathrm{i}}^{\mathrm{t}-1}\right)$

$+\sum_{i \in \mathcal{N} \cup \cup w} \sum_{p \in 0} C A_{i, 0} \cdot\left(y_{i, 0}^{t}\right.$

$\left.-y_{i, 0}^{t-1}\right) \leq D L^{t}+I N V^{t}$

Constraints (25)-(34) are related to net profit of supply chain in each period. Here we assume that there is an initial investment for the first period and development budget in each period is determined based on net profit computed by subtracting total cost from total revenue in previous periods. Total cost includes fixed costs of opening facility (26), adding capacity options to plants and warehouses (27), operating facility fixed cost (28), production variable costs (29), storage variable costs (30) transportation costs from supplier $s$ to plant $i$ (31), from warehouse $j$ to customer $c$ (32) and from plant $p$ to warehouse $j$ (33) and finally raw material supply costs (34). Constraint (35) calculates the expansion budget which is the net profit after tax and stakeholder share. Constraint (36) prevents the cost of opening facility and adding option to some opened facilities be more than expansion limitation in each period.

$$
\begin{aligned}
& y_{i o}^{t} \leq x_{i}^{t} \quad \forall i \in M \cup W p_{0} \forall o \in \mathcal{O} \\
& x_{i}^{t-1} \leq x_{i}^{t} \quad \forall i \in M \cup \mathcal{W P} \\
& m_{*} x_{j}^{t}-\sum_{t=t-1}^{t-m+1} x_{j}^{t}-\sum_{t=t+1}^{t+m-1} x_{j}^{t} \leq 1 \forall j \in W \mathcal{H} \\
& y_{i}^{t-1} \leq y_{i}^{t} \quad \forall i \in M \cup \mathcal{W}_{p}, 0 \in \mathcal{O} \\
& \sum_{\mathbb{E} \in \mathbb{C}} \sum_{p \in p_{f}} f_{p j e}^{t} \leq x_{j}^{t} \times B i g M \quad \forall j \in W \\
& \sum_{D \in \mathscr{D}} y_{i, 0}^{t} \leq 1 \quad \forall i \in M \subset \mathcal{W} \\
& y_{i}^{t}, \leq 1-\left(x_{i}^{t}-x_{i}^{t-1}\right) \quad \forall i \in M \cup W_{p, 0} \in \mathcal{O}
\end{aligned}
$$

Constraint (37) states that an opened facility can add available capacity options only. Constraint (38) prevents the opened facilities from closing. For the public warehouses, we suppose that they cannot be hired for less than $m$ periods, 
constraint (39) ensures this condition. Constraint (40) states that we can add new capacity options but we cannot remove them. Constraint (41) ensures that only opened warehouses can send product to customers. Equation (42) states that we cannot add more than one capacity option to a facility in one period, and constraint (43) prevents adding any facility option at the first period of opening a facility.

$$
\begin{aligned}
& x_{i}^{t} \in\{0,1\} \text {. } \\
& y_{\mu_{0}}^{t} \in\{0,1\} \text {. } \\
& z_{g p}^{t} \in\{0,1\} \\
& f_{p i, i^{r}}^{t} \geq 0 \\
& \theta_{p i \mathrm{i}}^{t} \geq 0 \\
& h_{p, j}^{t} \geq 0
\end{aligned}
$$

The constraints (44)-(46) require that these variables are binary. The constraints (47)-(49) restrict these variables from taking non-negative values.

\section{ILLUSTRATIVE EXAMPLE}

In order to illustrate the proposed model, with 3 suppliers, 3 potential locations for plants, 3 potential locations for warehouses and 3 customer zones a hypothetical example is used to show application of the proposed method. Three investment scenarios are evaluated to make our macro decisions assuming that the total available fund is $30,000,000$ that should be invested during the planning horizon. Table I shows the scenarios for investment in each period.

The following parameters are considered in this example:

- Number of suppliers=3

- Number of potential location for plant=3

- Number of potential location for warehouse=3

- Number of customer zone=3

- Number of time period $=5$

- Number of raw material=4

- Number of final product=2

- Number of capacity option=2

- Tax rate=0.1

- Stakeholders' share $=0.4$

TABLE I. SCENARIOS FOR INVESTMENT IN EACH PERIOD

\begin{tabular}{c|ccc}
\hline Periods & Scenario I & Scenario II & Scenario III \\
\hline 1 & $10,000,000$ & $20,000,000$ & $15,000,000$ \\
2 & $10,000,000$ & $10,000,000$ & $15,000,000$ \\
3 & $10,000,000$ & - & - \\
4 & - & - & - \\
5 & - & - & - \\
\hline
\end{tabular}

We assume that initial capacity of each plant and warehouse are 20000 and 100,000 respectively. Maximal installable capacity in each plant is 100,000 and in each warehouse is 200,000. Minimal and maximal percentages of utilization of a facility are 0.3 and 0.9 . Two capacity options are considered as 25000 and 50000 for facilities. Other parameters including cost elements, demands, available raw material in each supplier, etc. are presented in appendix. Here we should mention that the demands quantity are generated randomly between 16000 and 20000 and assumed that this amounts will be increased in the following periods with the rate of 30 percent. The model has been solved for all scenarios using GAMS 21.7. The results confirm that the second scenario is the best scenario for investment according to net present value (NPV) of the net profit as well as objective function. Tables 2-4 show the results for scenarios.

\section{Results of scenario II:}

As mentioned before, the proposed model has been developed for the design of four echelons, multiple products, and multiple periods supply chain. There are a lot of decisions are made using the proposed method such as supplier selection, plant location, warehouse location, production planning and the amount of finished product to be sent to each customer zone. The objective function is maximization of total net profit during the planning horizon. One of the most important features of this model that makes it more legalistic is that development of the supply chain during the planning horizon is limited to cumulative net profit after tax and stakeholders' share. Fig. 1 shows the net profit after tax and stakeholders' share in each period.

In the proposed model, variable $x_{i}^{t}$ determines the location of facilities and the time of opening facilities in the selected location. These facilities includes plants, public and private warehouses. In the case of warehouses indices 1 and 2 indicate candidate location for the private warehouse and index 3 indicates public warehouse. If a private facility opens, it cannot be closed till the end of planning horizon. Also a public warehouse cannot be hired for less than 3 periods. Table V shows amount of variable $x_{i}^{t}$.

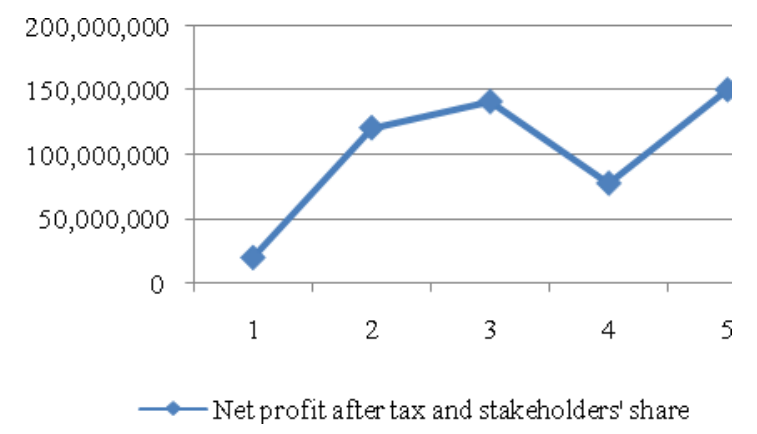

Fig.1. Net profit after tax and stakeholders' share in each period

As it can be seen in this table, two locations 2 and 3 are selected for the establishment of production units. The time of opening these plants is at the first period and they will remain opened till the last period. In the case of warehouses candidate public warehouse will be hired for 3 periods and location 2 has been selected for establishment of a private warehouse at the second period. 
TABLE II. RESULTS OF SCENARIO I

\begin{tabular}{c|ccc}
\hline & TABLE II. RESULTS OF SCENARIO I \\
\hline Time period & Investment & Net incomes & $\begin{array}{c}\text { Net profit after } \\
\text { tax and } \\
\text { stakeholders' } \\
\text { share }\end{array}$ \\
\hline 1 & $10,000,000$ & $20,308,160$ & $10,966,406$ \\
2 & $10,000,000$ & $121,455,100$ & $65,585,754$ \\
3 & $10,000,000$ & $141,888,800$ & $76,619,952$ \\
4 & & $78,197,350$ & $42,226,569$ \\
5 & & $151,065,400$ & $81,575,316$ \\
\hline $\begin{array}{c}\text { NPV of net } \\
\text { profit }\end{array}$ & $182,606,121$ & & \\
\hline $\begin{array}{c}\text { Objective } \\
\text { function }\end{array}$ & $512,914,700$ & & \\
\hline
\end{tabular}

TABLE III. RESULTS OF SCENARIO II

\begin{tabular}{|c|c|c|c|}
\hline Time period & Investment & Net incomes & $\begin{array}{l}\text { Net profit after } \\
\text { tax and } \\
\text { stakeholders' } \\
\text { share }\end{array}$ \\
\hline 1 & $20,000,000$ & $40,015,580$ & $21,608,413$ \\
\hline 2 & $10,000,000$ & $127,665,100$ & $68,939,154$ \\
\hline 3 & - & $150,886,800$ & $81,478,872$ \\
\hline 4 & - & $78,197,350$ & $42,226,569$ \\
\hline 5 & - & $151,065,400$ & $81,575,316$ \\
\hline $\begin{array}{l}\text { NPV of net } \\
\text { profit }\end{array}$ & $199,416,878$ & & \\
\hline $\begin{array}{l}\text { Objective } \\
\text { function }\end{array}$ & $542,769,800$ & & \\
\hline
\end{tabular}

\begin{tabular}{c|ccc}
\multicolumn{4}{c}{ TABLE IV. RESUlTs OF SCENARIO III } \\
\hline $\begin{array}{c}\text { Time } \\
\text { period }\end{array}$ & Investment & Net incomes & $\begin{array}{c}\text { Net profit after } \\
\text { tax and } \\
\text { stakeholders } \\
\text { share }\end{array}$ \\
\hline 1 & $15,000,000$ & $20,308,160$ & $10,966,406$ \\
2 & $15,000,000$ & $118,665,100$ & $64,079,154$ \\
3 & & $150,888,800$ & $81,479,952$ \\
4 & & $78,195,350$ & $42,225,489$ \\
5 & & $151,065,400$ & $81,575,316$ \\
\hline $\begin{array}{c}\text { NPV of net } \\
\text { profit }\end{array}$ & & & \\
\hline $\begin{array}{c}\text { Objective } \\
\text { function }\end{array}$ & & & \\
\hline
\end{tabular}

\begin{tabular}{|c|c|c|c|c|c|c|}
\hline & Time periods & 1 & 2 & 3 & 4 & 5 \\
\hline \multirow{3}{*}{$\frac{\vec{\Xi}}{\underline{a}}$} & 1 & 0 & 0 & 0 & 0 & 0 \\
\hline & 2 & 1 & 1 & 1 & 1 & 1 \\
\hline & 3 & 1 & 1 & 1 & 1 & 1 \\
\hline \multirow{3}{*}{ 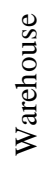 } & 1 & 0 & 0 & 0 & 0 & 0 \\
\hline & 2 & 0 & 1 & 1 & 1 & 1 \\
\hline & 3 & 1 & 1 & 1 & 0 & 0 \\
\hline
\end{tabular}

We can add capacity to an opened facility instead of establishment of a new facility. The model allows adding capacity only to an opened facility and an added capacity cannot be removed. Also the model prevents adding a capacity option to a facility at the first period of opening. Table VI shows amount of variable $y_{i, 0}^{t}$. The results indicate that capacity option 2 should be added to plant 3 at period 2 .

TABLE VI. AMOUNT OF VARIABLE $Y_{L_{2}^{E},}^{E}$

\begin{tabular}{c|c|c|c|c|c|c}
\hline \multicolumn{2}{|c|}{ Time periods } & 1 & 2 & 3 & 4 & 5 \\
\hline Plant & Capacity option & & & & & \\
3 & 2 & & 1 & 1 & 1 & 1 \\
\hline
\end{tabular}

Table VII shows amount of raw material transferred from each supplier to each plant in each period. Transportation cost from supplier to plants has not been taken into consideration in the price of unit raw material, thus it can be a criterion for the selection of suppliers and procurement planning.

\begin{tabular}{|c|c|c|c|c|c|c|c|}
\hline \multirow[b]{2}{*}{ 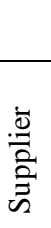 } & \multirow[b]{2}{*}{$\overrightarrow{\vec{\Xi}}$} & \multirow[b]{2}{*}{ 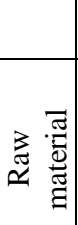 } & \multicolumn{5}{|c|}{ Time period } \\
\hline & & & 1 & 2 & 3 & 4 & 5 \\
\hline 1 & 2 & 1 & & & 8497 & 5400 & 13907 \\
\hline 1 & 2 & 3 & & & 16995 & 10800 & 27815 \\
\hline 1 & 2 & 4 & 22096 & & & & 13907 \\
\hline 1 & 3 & 1 & 11406 & & 52531 & 38454 & 44720 \\
\hline 1 & 3 & 2 & & 42340 & 1000 & & \\
\hline 1 & 3 & 3 & & 35841 & 28027 & 35667 & 19965 \\
\hline 1 & 3 & 4 & 20250 & 32100 & 45206 & & 38719 \\
\hline 2 & 2 & 1 & 24021 & 3000 & & & \\
\hline 2 & 2 & 2 & 11010 & & & & 13907 \\
\hline 2 & 2 & 3 & 48042 & 6000 & & & \\
\hline 2 & 2 & 4 & & 9000 & & 5400 & \\
\hline 2 & 3 & 1 & 8844 & 56829 & & & \\
\hline 2 & 3 & 2 & 10125 & & 73555 & 25575 & 58829 \\
\hline 2 & 3 & 3 & 40500 & 77818 & 53455 & & 52765 \\
\hline 2 & 3 & 4 & & 54265 & 23694 & 38454 & 12611 \\
\hline 3 & 2 & 2 & 1000 & 9000 & 25492 & 5400 & \\
\hline 3 & 2 & 4 & 1925 & & 25492 & & \\
\hline 3 & 3 & 1 & & & & & 33060 \\
\hline 3 & 3 & 2 & & 44025 & 22148 & 12879 & \\
\hline 3 & 3 & 3 & & & 23580 & 41241 & 82831 \\
\hline 3 & 3 & 4 & & & 27803 & & 26450 \\
\hline
\end{tabular}

Table VIII Shows quantity of manufactured products in each plant during the planning horizon. Products 1 and 2 will be produced in all periods in all plants. As it can be seen in this table there is a reduction in production at period 4 and it can be considered as main reason in decreasing net profit at this period has been illustrated in Fig.1. Trends of quantity of 
manufactured products during the planning horizon have been illustrated in Fig.2.

TABLE VIII. QUantity OF MANUfACtUREd PRODUCt IN EACH PLANT

\begin{tabular}{c|c|c|c|c|c|c}
\hline \multicolumn{2}{c|}{} & \multicolumn{5}{|c}{ Time period } \\
\cline { 1 - 2 } $\begin{array}{c}\text { Finished } \\
\text { product }\end{array}$ & Plant & 1 & 2 & 3 & 4 & 5 \\
\cline { 1 - 2 } 1 & 2 & 12010 & 1500 & 4248 & 2700 & 6953 \\
1 & 3 & 10125 & 28414 & 26265 & 19227 & 38890 \\
2 & 2 & 1489 & 3000 & 8497 & 1800 & 4635 \\
\hline 2 & 3 & 3375 & 28788 & 32234 & 12818 & 19609 \\
\hline
\end{tabular}

Table IX shows quantity of transferred finished products from plants to each warehouse in each period. As it can be seen from this table, at the first period both plants send their product to hired public warehouse but in the following periods no products will be sent to this warehouse. According to the predetermined condition for hiring public warehouse that it cannot be hired for less than 3 periods, it still remain opened at periods 2 and 3 but due to establishment of a private warehouse at the second period and with respect to its low variable storage cost, no products will be sent to public warehouse in periods 2 and 3 .

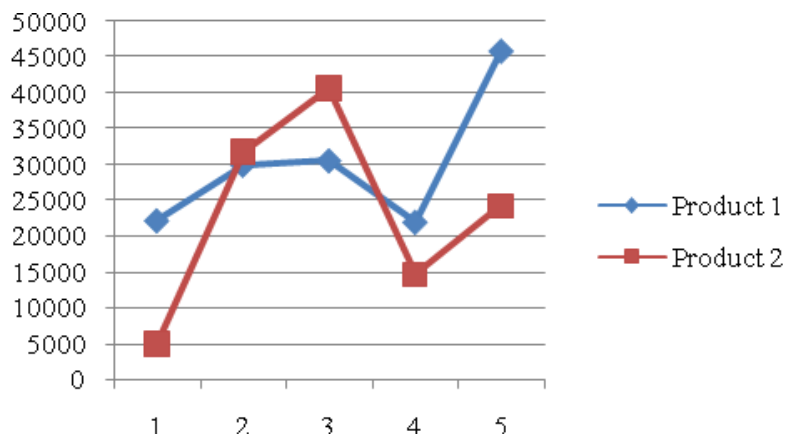

Fig.2. Trends of quantity of manufactured product in each period

TABLE IX. TRANSFERRED FINISHEd PROdUCTS From Plants To EACH WAREHOUSE

\begin{tabular}{|c|c|c|c|c|c|c|c|}
\hline \multirow[b]{2}{*}{$\frac{\vec{\Xi}}{\frac{\vec{\Xi}}{2}}$} & \multirow[b]{2}{*}{$\begin{array}{l}0 \\
0 \\
0 \\
\frac{0}{00} \\
\stackrel{0}{3}\end{array}$} & \multirow[b]{2}{*}{ 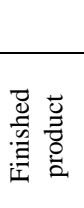 } & \multicolumn{5}{|c|}{ Time period } \\
\hline & & & 1 & 2 & 3 & 4 & 5 \\
\hline 2 & 5 & 1 & & 1500 & 4248 & 2700 & 6953 \\
\hline 2 & 5 & 2 & & 3000 & 8497 & 1800 & 4635 \\
\hline 2 & 6 & 1 & 12010 & & & & \\
\hline 2 & 6 & 2 & 1489 & & & & \\
\hline 3 & 5 & 1 & & 28414 & 26265 & 19227 & 38890 \\
\hline 3 & 5 & 2 & & 28788 & 32234 & 12818 & 19609 \\
\hline 3 & 6 & 1 & 10125 & & & & \\
\hline 3 & 6 & 2 & 3375 & & & & \\
\hline
\end{tabular}

In this paper demands are consider as total needs in market, so it's not necessary to satisfy all the demands. The proposed model aims to make a planning to send products to markets in order to maximize total profit. Table $\mathrm{X}$ shows quantity of finished product transferred from each warehouse to each customer zone. With respect to these results customer zone 3 received products only at the first period.

Fig.3 illustrates four echelons of the current numerical example. It can be seen in this figure that all suppliers are active in all periods. In the case of plants, locations 2 and 3 have been selected for establishment of production units at the first period. Public warehouse 3 will be hired at the first period for duration of 3 periods; also location 2 has been selected for establishment of a private warehouse at the second period. Customer zone 3 received products only at the first period, customer zone 1 received products in all periods except first period and customer zone 2 received products in all periods. Also supply chain network in the first period of the current numerical example has been illustrated in Fig.4.

TABLE X. Finished PRoduct TRANSFERRED From EACH WAREHOUSE TO EACH CUSTOMER ZONE

\begin{tabular}{|c|c|c|c|c|c|c|c|}
\hline \multicolumn{8}{|c|}{ TO EACH CUSTOMER ZONE } \\
\hline \multirow[b]{2}{*}{ 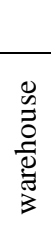 } & \multirow[b]{2}{*}{ 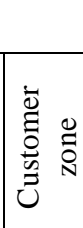 } & \multirow[b]{2}{*}{ 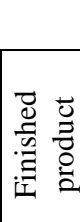 } & \multicolumn{5}{|c|}{ Time period } \\
\hline & & & 1 & 2 & 3 & 4 & 5 \\
\hline 2 & 1 & 2 & & 31788 & 40732 & 14618 & 24245 \\
\hline 2 & 2 & 1 & & 29914 & 30514 & 21927 & 45844 \\
\hline 3 & 2 & 2 & 4864 & & & & \\
\hline 3 & 3 & 1 & 22135 & & & & \\
\hline
\end{tabular}

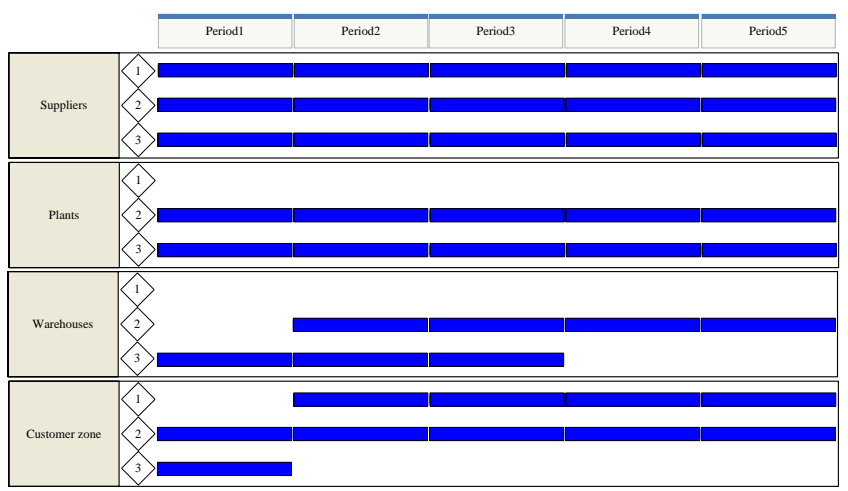

Fig.3. A schematic view on four echelons in the current numerical example 


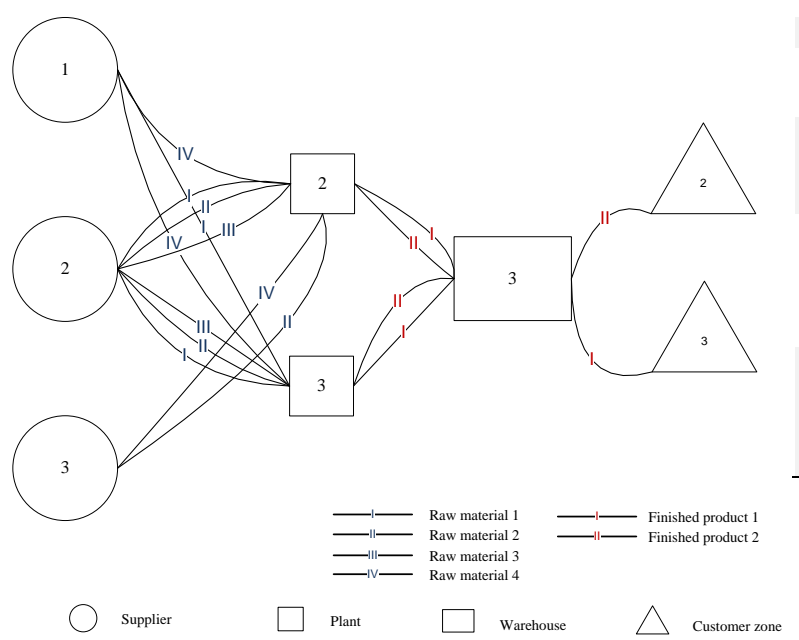

Fig.4. Supply chain network for the first period

\section{CONCLUSIONS}

Supply chain master planning is one of the most important strategic decisions in the current competitive business environment. Since that top managers try to make the best decisions about their company to ensure long term survival. Good supply chain design contributes them to reduce costs, increase products quality, delivering products to customers timely and as a result increasing total profit. In this regard planning supply chain expansion for a long term horizon is one of the most important strategic decisions.

This paper proposes a model for supply chain design, production and distribution planning and expansion planning. A four echelon, multiple commodity supply chain has been considered in a dynamic time horizon with objective function of maximization of total profit. Echelons include suppliers, production units, distribution centers and customer zones. The propose model makes strategic decisions including plant and warehouse location, type of warehouses (public or private) and decisions on adding capacity to opened facilities. Some tactical decisions are made such as quantity of raw material to be transferred from each supplier to plants, quantity of each product to be manufactured in each plant, quantity of finished product to be transferred from each production unit to each established warehouse and quantity of product to be transferred from each warehouse to each customer zone. One of the most important features of the propose model is that expansion of the supply chain is being planned with respect to cumulative net profit after tax and stakeholder's share. Also some constraints have been considered to make the proposed model more realistic. A numerical example has been designed, solved and analyzed to illustrate application of the proposed model.

\section{APPENDIX}

TABLE XI. SOME INPUT PARAMETERS FOR NUMERICAL EXAMPLE

\begin{tabular}{|c|c|c|c|c|c|}
\hline & \multicolumn{3}{|c|}{ Plants } & \multicolumn{2}{|c|}{ Private warehouse } \\
\hline & 1 & 2 & 3 & 1 & 2 \\
\hline Initial capacity & 15000 & 15000 & 15000 & 100000 & 100000 \\
\hline $\begin{array}{l}\text { Maximal } \\
\text { installable } \\
\text { capacity }\end{array}$ & 100000 & 100000 & 200000 & 200000 & 200000 \\
\hline Initial storage & - & - & - & 100000 & 100000 \\
\hline
\end{tabular}

\begin{tabular}{|c|c|c|c|c|c|}
\hline capacity & & & & & \\
\hline $\begin{array}{l}\text { fixed cost for } \\
\text { opening a facility }\end{array}$ & 8000000 & 9000000 & 9000000 & 1700000 & 2000000 \\
\hline $\begin{array}{lr}\text { fixed cost } & \text { for } \\
\text { operating } & a \\
\text { facility i } & \end{array}$ & 200000 & 220000 & 270000 & 80000 & 70000 \\
\hline $\begin{array}{l}\text { fixed cost for } \\
\text { operating facility } 1 \\
\text { for capacity } \\
\text { option 1 }\end{array}$ & 30000 & 30000 & 30000 & 20000 & 20000 \\
\hline $\begin{array}{l}\text { fixed cost for } \\
\text { operating facility } 1 \\
\text { for capacity } \\
\text { option 2 }\end{array}$ & 70000 & 70000 & 70000 & 40000 & 40000 \\
\hline
\end{tabular}

TABLE XII. AVAILABLE CAPACITY OF SUPPLIER S For RAW MATERIAL P AT PERIOD T

\begin{tabular}{|c|c|c|c|c|c|c|}
\hline \multirow[b]{2}{*}{ Supplier } & \multirow[b]{2}{*}{$\begin{array}{c}\text { Raw } \\
\text { material }\end{array}$} & \multicolumn{5}{|c|}{ Periods } \\
\hline & & 1 & 2 & 3 & 4 & 5 \\
\hline 1 & 1 & 11406 & 0 & 67822 & 83698 & 58628 \\
\hline 1 & 2 & 57224 & 42340 & 22261 & 56823 & 0 \\
\hline 1 & 3 & 0 & 35841 & 45022 & 94196 & 47781 \\
\hline 1 & 4 & 42346 & 32100 & 45206 & 0 & 52627 \\
\hline 2 & 1 & 78443 & 74861 & 22245 & 85521 & 0 \\
\hline 2 & 2 & 56832 & 0 & 73555 & 25575 & 72737 \\
\hline 2 & 3 & 88542 & 83818 & 53455 & 0 & 52765 \\
\hline 2 & 4 & 0 & 83531 & 23694 & 43854 & 12611 \\
\hline 3 & 1 & 72912 & 52716 & 0 & 82368 & 62679 \\
\hline 3 & 2 & 87344 & 53025 & 75842 & 92373 & 0 \\
\hline 3 & 3 & 0 & 0 & 23580 & 41241 & 82831 \\
\hline 3 & 4 & 80613 & 62371 & 53296 & 0 & 61238 \\
\hline
\end{tabular}

TABLE XIII. DEMAND OF CUSTOMER C For PRODUCT P AT T

\begin{tabular}{|c|c|c|c|c|c|c|}
\hline \multirow[b]{2}{*}{ Customer } & \multirow[b]{2}{*}{ Product } & \multicolumn{5}{|c|}{ Periods } \\
\hline & & 1 & 2 & 3 & 4 & 5 \\
\hline 1 & 1 & 119025 & 154733 & 201152 & 261498 & 339947 \\
\hline 1 & 2 & 108685 & 141291 & 183678 & 238781 & 310415 \\
\hline 2 & 1 & 121008 & 157310 & 204504 & 265855 & 345611 \\
\hline 2 & 2 & 110186 & 143242 & 186214 & 242079 & 314702 \\
\hline 3 & 1 & 125705 & 163417 & 212441 & 276174 & 359026 \\
\hline 3 & 2 & 107993 & 140391 & 182508 & 237261 & 308439 \\
\hline
\end{tabular}

TABLE XIV. QUANTITY OF RAW MATERIAL P' NECESSARY TO MANUFACTURE A UNIT OF FINAL PRODUCT P

\begin{tabular}{c|llll}
\hline \multirow{2}{*}{ Final product } & \multicolumn{4}{|c}{ Raw material } \\
\cline { 2 - 5 } & 1 & 2 & 3 & 4 \\
\hline 1 & 2 & 1 & 4 & 2 \\
2 & 1 & 3 & 2 & 3 \\
\hline
\end{tabular}

TABLE XV. WORKLOAD FOR THE TREATMENT OF A UNIT P AT FACILITY I

\begin{tabular}{c|ccccc}
\hline \multirow{2}{*}{ Final product } & \multicolumn{5}{|c}{ Facility } \\
\cline { 2 - 6 } & 1 & 2 & 3 & 4 & 5 \\
\hline 1 & 1 & 1 & 1 & 1 & 1 \\
2 & 1 & 1 & 1 & 1 & 1 \\
\hline
\end{tabular}

TABLE XVII. NUMBER OF DELIVERIES FROM PLANT ITO WAREHOUSE J IN ONE PERIOD

\begin{tabular}{c|ccc}
\hline \multicolumn{4}{|c}{ ONE PERIOD } \\
\hline \multirow{2}{*}{ Plant } & 1 & 2 & 3 \\
\cline { 2 - 4 } & 2 & 3 & 3 \\
2 & 1 & 2 & 2 \\
3 & 2 & 3 & 2 \\
\hline
\end{tabular}

TABLE XVIII. SELling PRICE OF ITEM OF UNIT P TO CUSTOMER C 


\begin{tabular}{c|ccc}
\hline \multirow{2}{*}{ Final product } & \multicolumn{3}{|c}{ Customer } \\
\cline { 2 - 4 } & 1 & 2 & 3 \\
\hline 1 & 2500 & 2500 & 2500 \\
2 & 2300 & 2300 & 2300 \\
\hline
\end{tabular}

TABLE XIX. PRICE OF RAW MATERIAL P FROM SUPPLIER S

\begin{tabular}{c|ccc}
\hline \multirow{2}{*}{ Raw material } & \multicolumn{3}{c}{ Supplier } \\
\cline { 2 - 4 } & 1 & 2 & 3 \\
\hline 1 & 23 & 27 & 29 \\
2 & 17 & 14 & 14 \\
3 & 19 & 15 & 18 \\
4 & 10 & 12 & 13 \\
\hline
\end{tabular}

\begin{tabular}{c|ccccc}
\multirow{2}{*}{ TABLE XX. FIXED COST FOR ADDING CAPACITY OPTION O TO FACILITY I } \\
\hline \multirow{2}{*}{$\begin{array}{c}\text { Capacity } \\
\text { option }\end{array}$} & 1 & 2 & 3 & 4 & 5 \\
\cline { 2 - 6 } & 800000 & 700000 & 700000 & 250000 & 300000 \\
1 & 1500000 & 1350000 & 1200000 & 400000 & 540000 \\
\hline
\end{tabular}

TABLE XXI. TREATMENT COST OF A UNIT P AT PLANT I

\begin{tabular}{c|ccc}
\hline \multirow{2}{*}{ Final product } & \multicolumn{3}{c}{ Plant } \\
\cline { 2 - 4 } & 1 & 2 & 3 \\
\hline 1 & 35 & 30 & 25 \\
2 & 40 & 35 & 30 \\
\hline
\end{tabular}

TABLE XXII. STORAGE COST OF A UNIT OF P AT WAREHOUSE J

\begin{tabular}{c|ccc}
\hline \multirow{2}{*}{ Final product } & \multicolumn{3}{c}{ Warehouse } \\
\cline { 2 - 4 } & 1 & 2 & 3 \\
\hline 1 & 8 & 7 & 45 \\
2 & 6 & 5 & 35 \\
\hline
\end{tabular}

TABLE XXIII. TRANSPORTATION COST OF A UNIT OF P FROM

\begin{tabular}{|c|c|c|c|c|}
\hline \multirow{2}{*}{ Raw material } & \multirow{2}{*}{ supplier } & \multicolumn{3}{|c|}{ Plant } \\
\hline & & 1 & 2 & 3 \\
\hline 1 & 1 & 6 & 4 & 5 \\
\hline 1 & 2 & 7 & 3 & 6 \\
\hline 1 & 3 & 9 & 9 & 8 \\
\hline 2 & 1 & 4 & 8 & 8 \\
\hline 2 & 2 & 3 & 5 & 4 \\
\hline 2 & 3 & 8 & 5 & 9 \\
\hline 3 & 1 & 6 & 4 & 5 \\
\hline 3 & 2 & 7 & 3 & 6 \\
\hline 3 & 3 & 9 & 9 & 5 \\
\hline 4 & 1 & 4 & 4 & 8 \\
\hline 4 & 2 & 3 & 5 & 4 \\
\hline 4 & 3 & 8 & 3 & 6 \\
\hline
\end{tabular}

TABLE XXIV. TRANSPORTATION COST OF A UNIT OF P FROM

\begin{tabular}{c|c|ccc}
\multicolumn{5}{|c}{ PLANT I TO WAREHOUSE J } \\
\hline \multirow{2}{*}{ Final product } & \multirow{2}{*}{ Plant } & \multicolumn{3}{|c}{ Warehouse } \\
\cline { 3 - 5 } & & 1 & 2 & 3 \\
\hline 1 & 1 & 5 & 7 & 6 \\
1 & 2 & 6 & 8 & 8 \\
1 & 3 & 8 & 4 & 5 \\
2 & 1 & 5 & 8 & 4 \\
2 & 2 & 8 & 4 & 8 \\
2 & 3 & 3 & 6 & 5 \\
\hline
\end{tabular}

TABLE XXV. TRANSPORTATION COST OF A UNIT OF P FROM WAREHOUSE J TO CUSTOMER ZONE C

\begin{tabular}{c|c|ccc}
\hline \multirow{2}{*}{ Final product } & \multirow{2}{*}{ Warehouse } & \multicolumn{3}{|c}{ Customer zone } \\
\cline { 3 - 5 } & & 1 & 2 & 3 \\
\hline 1 & 1 & 6 & 4 & 5 \\
1 & 2 & 7 & 3 & 6 \\
1 & 3 & 9 & 9 & 8 \\
2 & 1 & 4 & 8 & 8 \\
2 & 2 & 3 & 5 & 4 \\
2 & 3 & 8 & 5 & 9 \\
\hline
\end{tabular}

\section{REFERENCES}

[1] Amiri, A., (2006). Designing a distribution network in a supply chain system: Formulation and efficient solution procedure. European Journal of Operational Research, 171: 567-576.

[2] Arntzen, B.C., Brown, G.G., Terry p. Harrison, T.P., Trafton, L.L., (1995). Global Supply Chain Management at Digital quipment Corporation. INTERFACES, 25: 69-93.

[3] Cordeau, J.F., Pasin, F., Solomon, M.M., (2006). An integrated model for logistics network design. Annals of Operations Research, 144 (1): 59-82.

[4] Hamer-Lavoie, G., Cordeau, J.F., (2006). Un modéle pour la conception d'un réseau de distribution avec localisation, affectation et stocks. INFOR, 44: 99-115.

[5] Dias, J., Captivo, M.E., Climaco, J., (2006). Capacitated dynamic location problems with opening, closure and reopening of facilities. IMA Journal of Management Mathematics, 17 (4): 17-348.

[6] Goetschalckx, Vidal, C.J., Dogan, K., (2002). Modeling and design of global logistics systems: A review of integrated strategic and tactical models and design algorithms. European Journal of Operational Research, 143: 1-18.

[7] Melo, M.T., Nickel, S., Saldanha da Gama, F., (2006). Dynamic multi-commodity capacitated facility location: A mathematical modeling framework for strategic supply chain planning. Computers \& Operations Research 33: 181-208.

[8] Noorul Haq, A., Kannan, G., (2006). Design of an integrated supplier selection and multiechelon distribution inventory model in a built-to-order supply chain environment. International Journal of Production Research, 44 (10): 1963-1985.

[9] Park, Y.B., (2005). An integrated approach for production and distribution planning in supply chain management, International Journal of Production Research, 43 (6): 1205-1224.

[10] Thanha, P.N., Bostelb, N., Pétona, O., (2008). A dynamic model for facility location in the design of complex supply chains. International Journal of Production Economics (in press).

[11] Wouda, F.H.E., Beek, P.V., Van Der Vorst, J.G.A.J., Tacke, H., (2002). An application of mixed-integer linear programming models on the redesign of the supply network of Nutricia Dairy \& Drinks Group in Hungary. OR Spectrum, 24: 449-465. 